\title{
Effect of zirconium oxide and cellulose nanoparticles addition on the flexural strength, impact strength and translucency of heat polymerized acrylic resin: an in vitro study
}

\author{
Senbagavalli S Sagadevan $\mathrm{K}^{1,}$, $\mathrm{R}$ Ravichandran², K Harsha Kumar ${ }^{2}$, Vivek V Nair ${ }^{2}$, \\ Janardanan Kavitha ${ }^{3}$, VS Deepthi ${ }^{3}$ \\ ${ }^{1}$ Junior Resident, ${ }^{2}$ Professor, ${ }^{3}$ Assistant Professor, Department of Prosthodontics, Government Dental \\ College, Thiruvananthapuram, Kerala, India.
}

\section{N F O R M A T I O N}

\section{Article History}

Received 25th July 2021

Accepted 17th October 2021

Available online

$1^{\text {st }}$ December 2021

\section{K E Y W O R D S}

Polymethylmethacrylate

Zirconium oxide nanoparticles

Cellulose nanoparticles

Flexural strength

Impact strength

Translucency
Background: Polymethyl methacrylate denture base material is considered the most popular denture base material to date. The advantages of the PMMA include low cost, biocompatibility, ease of processing, stability in the oral environment, and acceptable aesthetics. To improve the acrylic polymer's properties for removable acrylic appliances, the significant issues to be addressed are its low mechanical properties such as impact, bending, and fatigue.

Aim: This study was aimed to evaluate the effect of incorporating different concentrations of zirconium oxide and cellulose nanoparticles on flexural strength, and impact strength and translucency of heat polymerized acrylic resin.

Materials and methods: A total of 180 acrylic specimens were made and divided into two groups, which comprises 90 specimens in each. Group I and Group II were reinforced with $\mathrm{ZrO}_{2}$ and cellulose nanoparticles, respectively. Each group was divided into three subgroups depending on the properties to be evaluated i.e., flexural strength, Impact strength, and Translucency, respectively. Each subgroup was further divided into three based on the concentrations (1.5 wt\%, 2.5 $w t \%$ and $5.0 \mathrm{wt} \%)$ of the nanoparticles. The flexural strength was determined using a universal testing machine. The Izod impact tester was used to evaluate the impact strength. Translucency measured by UV visible spectrophotometer. The obtained data were analysed using one way ANOVA within the group followed by posthoc comparison by TUKEY'S method for the comparison between groups.

Results: Acrylic specimens incorporated with 2.5 wt $\% \mathrm{ZrO}_{2}$ exhibited more mean flexural strength, and the specimens with $2.5 \mathrm{wt} \%$ and $5.0 \mathrm{wt} \%$ cellulose nanoparticles showed the highest impact strength and translucency, respectively. One-way ANOVA showed significant differences $(p=0.000)$ between the groups.

Conclusion: PMMA incorporated with $2.5 \mathrm{wt} \%$ of $\mathrm{ZrO}_{2} \mathrm{NPs}, 2.5 \mathrm{wt} \%$ and 5.0 wt\% of cellulose NPs showed superior flexural strength, impact strength, and translucency, respectively.

\section{Introduction}

An ideal denture base material should have adequate mechanical and physical properties, besides biocompatibility and aesthetics[1]. In 1937, Dr Walter Wright

Correspondence: ${ }^{*}$ Corresponding author Email Address: drshenbagavallibds@gmail.com

How to cite this article: Sagadevan KSS, Ravichandran R, Harsha Kumar K, Nair VV, Kavitha J, Deepthi VS. Effect of zirconium oxide and cellulose nanoparticles addition on the flexural strength, impact strength and translucency of heat polymerized acrylic resin: an in vitro study. Int J Dent Mater 2021;3(4): 112-119.

DOI: http://dx.doi.org/10.37983/IJDM.2021.3403 
introduced Poly Methyl Methacrylate (PMMA) denture base material, which is considered the most popular denture base material to date [2]. The advantages of the PMMA include low cost, biocompatibility, ease of processing, stability in the oral environment, and acceptable aesthetics [3]. In order to improve the acrylic polymer's properties for removable acrylic appliances and dentures, the important issues to be addressed are its low mechanical properties against impact, bending, and fatigue [4]. Hence, PMMA cannot be considered an ideal material because of its inferior physical and mechanical properties.

To improve mechanical and physical properties, various nanoparticles (NP) have been added to different dental materials like Zirconium oxide $\left(\mathrm{ZrO}_{2}\right)$, copper oxide ( $\mathrm{CuO})$, silver $(\mathrm{Ag})$, silicon dioxide $\left(\mathrm{SiO}_{2}\right)$, zinc oxide ( $\mathrm{ZnO})$, titanium dioxide $\left(\mathrm{TiO}_{2}\right)$, etc. Among these, Zirconium nanoparticles received great attention because of their superior mechanical and esthetic properties [5]. Nano cellulose is a natural renewable polymer derived from plants and wood pulp, used to increase the strength and hardness of the material [6]. Another important parameter that governs the success of a complete denture is its translucency. Translucency is one of the major parameters when esthetics is considered and several nanoparticles have been added to improve the translucency of PMMA.

Previous studies suggested that the addition of Zirconium oxide and Cellulose nanofillers to PMMA improved mechanical properties such as flexural strength, fracture toughness, and hardness [7]. However, the translucency denture prosthesis was adversely affected and reduced as the nano $\mathrm{ZrO}_{2}$ concentration was increased [8].

Though several studies have evaluated the effects of nanoZrO $\mathrm{Z}_{2}$ and nanocellulose inclusion on the properties of PMMA denture base material, there is limited literature on comparing the effects of nanoZrO $\mathrm{Zr}_{2}$ and nanocellulose incorporation on the properties of PMMA. The purpose of this study was to assess and compare the effects of zirconium oxide and cellulose nanoparticles added in concentrations of $1.5 \mathrm{wt} \%$, $2.5 w t \%$, and $5 w t \%$ on the flexural strength, impact strength, and translucency, respectively of heat polymerized acrylic resin.

2. Materials and methods

\subsection{Incorporation of $\mathrm{ZrO}_{2}$ and cellulose nanoparticles into PMMA heat cure resin}

$\mathrm{ZrO}_{2}$ nanoparticles (Nanoshel, India; Purity - 99.9\%, Average particle size - $20 \mathrm{~nm}$ ) were incorporated into the polymer of heat cure acrylic resin (DPI Heat Cure, the Bombay Burmah trading corporation Itd, India) at three different concentrations, viz. $1.5 \%$ and $2.5 \%$ and $5.0 \%$ by weight. The appropriate amount of $\mathrm{ZrO}_{2}$ and acrylic resin were weighed using a digital weighing balance and were mixed using a mortar and pestle. To ensure uniform distribution of $\mathrm{ZrO}_{2}$ in the polymer of heat cure acrylic resin "geometric dilution" method was employed for trituration. The insertion of cellulose nanoparticles (Nanoshel, India; purity - 99.9\%, average particle size $-20 \mathrm{~nm}$ ) followed a similar approach.

\subsection{Fabrication of test specimens}

Rectangular specimens were fabricated for measuring the flexural strength, impact strength and translucency. The dimensions of the rectangular specimens were $65 \times 10 \times 3 \mathrm{~mm}$ for flexural strength, $80 \times 4 \times 10 \mathrm{~mm}$ for impact strength, and $15 \times 12 \times 2 \mathrm{~mm}$. Plexiglass moulds of the above-mentioned dimensions were fabricated with high precision laser cutting machine. Wax patterns were prepared from plexiglass moulds and were invested. The monomer and polymer of the heat polymerized acrylic resin were proportioned, mixed, packed, and pressed into the mould following the manufacturer's instructions. After closing the lid of the flask, it was subjected to 200 pascal loads using a hydraulic bench press. The flasks were bench cured for 30 minutes and processed at $74^{\circ} \mathrm{C}$ for 2 hours and then at $100^{\circ} \mathrm{C}$ and for 1 hour. After completion of the curing cycle, the flasks were removed from the water bath and allowed to cool slowly to room temperature. All the specimens were stored in distilled water at $37 \pm 1^{\circ} \mathrm{C}$ for 7 days, before testing.

\subsection{Flexural strength evaluation}

The flexural strength of the specimens was evaluated according to the ISO 1567, 1999 for denture base resins by a three-point bending test using a Universal testing machine (Instron, Maeon laboratories, Chennai, India). The rectangular specimens were inserted in relative points on the testing machine such that the span length was $50 \mathrm{~mm}$. The samples were stressed at a crosshead speed of $5 \mathrm{~mm} / \mathrm{min}$ until fracture occurred. 
Flexural strength was calculated using the following equation.

$$
\mathrm{S}=3 \mathrm{FL} / 2 \mathrm{bd}^{2}
$$

Where,

S: Flexural strength

F: Force of wedge to the middle of specimen

L: Distance between supporting wedges

b: Width of specimen

d: Thickness of specimen

\subsection{Impact strength evaluation}

The IZOD impact tester (Maeon laboratories, Chennai, India) was used to evaluate the impact strength of each specimen. IZOD is a pendulum impact machine consisting of a base, a pendulum and a striker rod. The rectangular specimens were inserted in the anvil or support to receive the blow of moving mass.

For plastic-type material like the acrylics, the pendulum apparatus imparting the load was a half-disc shape. The energy of the pendulum alone was 2.7J. Initially, the machine was calibrated to reduce the error, the test specimen was held tightly in the anvil, and the pendulum is then released from its latch. Pendulum swings down gaining energy from gravitational force and the height from which it is released. It hits onto the specimen, and the specimen breaks, and the pendulum swings to the other side. The energy required to fracture the specimen was measured in $\mathrm{KJ} / \mathrm{m}^{2}$.

\subsection{Translucency evaluation}

Light transmittance was measured using UV Visible Spectrophotometer (Varian, CARY 100 BIO, LabX, Canada). Light transmittance has been used as a translucency measure because it is a property of a substance that allows light to pass through it partially. UV/VIS spectroscopy is based on the absorption of light by a sample. Valuable information can be obtained based on the amount of light absorbed by the sample and its wavelength.

A spectrophotometer with a double prism monochromator to create the light of any desired wavelength, a photometer with a silicon photodetector to measure light intensity, and a sample holder made up the spectrophotometer. The equipment was set up such that specimens could be positioned between the spectrometer beam and the photometer at the inte- grating sphere's entrance port to measure the total amount of light transmitted and dispersed through it.

\section{Results}

The data were analysed using Statistical Package for Social Sciences (SPSS) version 16.0 software. Data obtained was expressed in its mean and standard deviation. Analysis of Variance (One Way ANOVA) was performed as a parametric test to compare different groups. In order to facilitate multiple comparisons between groups, Tukey's method was employed as a post hoc test along with ANOVA. For all statistical evaluations, a two-tailed probability of value less than 0.05 was considered significant.

The mean and standard deviations of flexural strength, impact strength and translucency of acrylic specimens incorporated with various concentrations of Zirconia and Cellulose NPs are presented in table 1 . The maximum mean flexural strength was exhibited by the specimens incorporated with $2.5 \% \mathrm{ZrO}_{2}$ and $5.0 \%$ cellulose NPs. Maximum mean impact strength was observed in the acrylic specimens modified with $1.5 \%$ $\mathrm{ZrO}_{2}$ and $2.5 \%$ cellulose NPs. The denture base acrylic specimens modified with $1.5 \mathrm{wt} \%$ of $\mathrm{ZrO}_{2}$ and $5.0 \mathrm{wt} \%$ of Cellulose NPs showed more translucency (Table 1). One-way ANOVA showed statistically significant differences ( $p=0.000)$ among the various concentrations of nanoparticles incorporated acrylic specimens in all the tested properties (Table 1).

Multiple comparisons with post hoc by Tukey's method revealed that the acrylic specimens incorporated with 5.0wt \% of Cellulose NPs exhibited significant differences with $1.5 \mathrm{wt} \%(p=0.001)$ and $2.5 \mathrm{wt} \%$ ( $p=0.0001)$ of Cellulose NPs in the flexural strength. A significant difference $(p=0.032)$ was observed in impact strength between $1.5 \mathrm{wt} \%$ and $5.0 \mathrm{wt} \%$ of $\mathrm{ZrO}_{2}$ NPs incorporated specimens. In translucency, acrylic specimens modified with 5.0 wt\% Cellulose NPs showed significant differences with 1.5 wt $\%$ ( $p=0.0073)$ and 2.5 wt $\%(p=0.0406)$ of Cellulose NPs. Significant differences $(p=0.000)$ were observed between the acrylic specimens incorporated with $\mathrm{ZrO}_{2}$ NPs at all concentrations (Table 2).

Multiple comparisons with post hoc analysis between the two different nanoparticles at different concentrations showed significant differences in flexural strength between all the concentrations except 5.0 


\begin{tabular}{|c|c|c|c|c|c|c|}
\hline Properties & Nanoparticles & $\mathbf{N}$ & $1.5 w t \%$ & $2.5 w t \%$ & $5 w t \%$ & p value \\
\hline Flexural & Zirconia & 10 & $72.02+2.40$ & $76.37+5.06$ & $72.42+4.50$ & $0.00^{*}$ \\
\hline Strength (MPa) & Cellulose & 10 & $64.42+2.84$ & $60.97+2.01$ & $71.47+3.64$ & $0.00^{*}$ \\
\hline Impact & Zirconia & 10 & $1.34 \pm 0.11$ & $0.83 \pm 0.26$ & $1.03 \pm 0.27$ & $0.00^{*}$ \\
\hline $\begin{array}{l}\text { Strength } \\
\left(\mathrm{KJ} / \mathrm{m}^{2}\right)\end{array}$ & Cellulose & 10 & $0.95 \pm 0.34$ & $1.37 \pm 0.52$ & $1.32 \pm 0.48$ & $0.00^{*}$ \\
\hline \multirow{2}{*}{ Translucency } & Zirconia & 10 & $45.91 \pm 1.49$ & $32.97 \pm 1.73$ & $24.22 \pm 2.66$ & $0.00^{*}$ \\
\hline & Cellulose & 10 & $51.79 \pm 3.12$ & $52.39 \pm 1.60$ & $55.31 \pm 1.68$ & $0.00^{*}$ \\
\hline
\end{tabular}

*statistically significant difference was observed.

Table 2. Multiple group comparison of flexural strength, and translucency of acrylic

specimens modified with various concentrations of Cellulose and Zirconia NPs using Tukey's post hoc test

\begin{tabular}{|c|c|c|c|c|c|c|}
\hline \multirow{2}{*}{$\begin{array}{l}\text { Nanopar- } \\
\text { ticles }\end{array}$} & \multirow{2}{*}{\multicolumn{2}{|c|}{ Concentrations }} & \multicolumn{2}{|c|}{ Flexural Strength } & \multicolumn{2}{|c|}{ Translucency } \\
\hline & & & $\mathbf{M D}^{*} \pm \mathrm{SE} !$ & $\begin{array}{c}\text { Significance } \\
(p \text {-value })\end{array}$ & $\mathrm{MD}^{*} \pm \mathrm{SE} !$ & $\begin{array}{c}\text { Significance } \\
(p \text {-value })\end{array}$ \\
\hline \multirow{3}{*}{ Cellulose } & \multirow{2}{*}{$1.5 w \mathrm{t} \%$} & $2.5 w t \%$ & $3.45 \pm 1.601$ & 0.276 & $0.597 \pm 0.962$ & 0.989 \\
\hline & & $5.0 \mathrm{wt} \%$ & $7.051 \pm 1.601$ & 0.001 & $3.518 \pm 0.962$ & 0.0073 \\
\hline & $2.5 w t \%$ & $5.0 \mathrm{wt} \%$ & $10.5 \pm 1.601$ & 0.0001 & $12.94 \pm 0.962$ & 0.0406 \\
\hline \multirow{3}{*}{ Zirconia } & \multirow{2}{*}{$1.5 \mathrm{wt} \%$} & $2.5 w t \%$ & $4.349 \pm 1.601$ & 0.089 & $21.69 \pm 0.962$ & 0.000 \\
\hline & & $5.0 w t \%$ & $0.398 \pm 1.601$ & 1.000 & $8.751 \pm 0.962$ & 0.000 \\
\hline & $2.5 w \mathrm{t} \%$ & $5.0 \mathrm{wt} \%$ & $3.951 \pm 1.601$ & 0.152 & $0.597 \pm 0.962$ & 0.000 \\
\hline
\end{tabular}

* Mean difference, ! Standard error

Table 2. Multiple group comparison of flexural strength, and translucency of acrylic specimens modified with various concentrations of Cellulose and Zirconia NPs using Tukey's post hoc test

\begin{tabular}{|c|c|c|c|c|c|c|c|}
\hline \multicolumn{2}{|c|}{ Nanoparticles } & \multicolumn{2}{|c|}{ Flexural Strength } & \multicolumn{2}{|c|}{ Impact Strength } & \multicolumn{2}{|l|}{ Translucency } \\
\hline Cellulose & Zirconia & $\mathrm{MD}^{*} \pm \mathrm{SE} !$ & $\begin{array}{c}\text { Signifi- } \\
\text { cance } \\
\text { (p-value) }\end{array}$ & $\mathrm{MD}^{*} \pm \mathrm{SE} !$ & $\begin{array}{c}\text { Signifi- } \\
\text { cance } \\
\text { (p-value) }\end{array}$ & $\mathrm{MD}^{*} \pm \mathrm{SE} !$ & $\begin{array}{c}\text { Signifi- } \\
\text { cance } \\
\text { (p-value) }\end{array}$ \\
\hline & $1.5 w \mathrm{t} \%$ & $7.606 \pm 1.601$ & 0.000 & $0.387 \pm 1.601$ & 0.171 & $5.876 \pm 0.962$ & 0.000 \\
\hline \multirow[t]{3}{*}{$1.5 \mathrm{wt} \%$} & $2.5 w \mathrm{t} \%$ & $11.96 \pm 1.601$ & 0.000 & $0.116 \pm 1.601$ & 0.978 & $18.82 \pm 0.962$ & 0.000 \\
\hline & $5.0 \mathrm{wt} \%$ & $8.004 \pm 1.601$ & 0.000 & $0.083 \pm 1.601$ & 0.995 & $27.57 \pm 0.962$ & 0.000 \\
\hline & $1.5 w \mathrm{t} \%$ & $11.06 \pm 1.601$ & 0.000 & $0.031 \pm 1.601$ & 0.99 & $6.473 \pm 0.962$ & 0.000 \\
\hline \multirow[t]{3}{*}{$2.5 \mathrm{wt} \%$} & $2.5 w t \%$ & $15.41 \pm 1.601$ & 0.000 & $0.534 \pm 1.601$ & 0.019 & $19.42 \pm 0.962$ & 0.000 \\
\hline & $5.0 \mathrm{wt} \%$ & $11.45 \pm 1.601$ & 0.000 & $0.335 \pm 1.601$ & 0.310 & $28.17 \pm 0.962$ & 0.000 \\
\hline & $1.5 \mathrm{wt} \%$ & $0.555 \pm 1.601$ & 0.999 & $0.015 \pm 1.601$ & 0.99 & $9.394 \pm 0.962$ & 0.000 \\
\hline \multirow[t]{2}{*}{$5.0 w \mathrm{t} \%$} & $2.5 w t \%$ & $4.904 \pm 1.601$ & 0.038 & $0.488 \pm 1.601$ & 0.040 & $22.34 \pm 0.962$ & 0.000 \\
\hline & $5.0 w t \%$ & $0.953 \pm 1.601$ & 0.991 & $0.289 \pm 1.601$ & 0.474 & $31.09 \pm 0.962$ & 0.000 \\
\hline
\end{tabular}

* Mean difference, ! Standard error 
wt $\%$ of Cellulose NPs with 1.5 wt\% and 5.0 wt\% of $\mathrm{ZrO}_{2}$ NPs. Incorporation of 2.5 wt $\%$ of $\mathrm{ZrO}_{2}$ NPs exhibited significant differences with acrylic resin specimens modified by 2.5 wt $\%$ and 5.0 wt $\%$ Cellulose NPs in impact strength. In translucency, significant differences were observed between both the NPs at all concentrations (Table 3).

\section{D iscussion}

The Polymethyl methacrylate (PMMA) is used to fabricate denture bases due to its various advantages, including low cost, biocompatibility, ease of processing, stability in the oral environment, and acceptable aesthetics [3]. As discussed in the literature, one of the major shortcomings of PMMA is its inadequate mechanical and physical properties such as low flexural strength (FS), impact strength (IS) and surface hardness that leads to the reduced clinical performance of the denture. This ultimately leads to reduced clinical life of the prostheses [4]. The translucency of the denture base of a removable prosthesis determines its esthetic outcome [7]. The addition of various nanoparticles has been shown to increase the translucency of PMMA.

Various nanoparticles (NP) have been added to different dental materials to improve their properties. Among these NPs, nano- $\mathrm{ZrO}_{2}$ received great attention due to its excellent toughness and mechanical strength, enabling it to withstand crack propagation. In addition, they have improved abrasion and corrosion resistance, and are highly biocompatible. They are also less likely to alter the aesthetics compared to other metal oxides because of their white colour [5]. Nano cellulose is a natural renewable polymer derived from plants and wood pulp, the most abundant, biocompatible, costeffective, easily available option to increase the strength and hardness of the material [6]. Several studies have been done earlier to evaluate the effect of zirconia and cellulose nanoparticles on PMMA. However, their effect on the properties of PMMA has not been compared to date. This study was conducted to evaluate and compare the flexural strength, impact strength and translucency of heat polymerized acrylic resin incorporated with $1.5 \mathrm{wt} \%, 2.5 \mathrm{wt} \%$ and $5.0 \mathrm{wt} \%$ of zirconium oxide and cellulose nanoparticles.

In this study, the acrylic resin incorporated with 2.5 wt. $\% \mathrm{ZrO}_{2}$ showed the highest mean flexural strength among all the concentrations of both the NPs. At 5.0 wt $\%$ of $\mathrm{ZrO}_{2}$ NPs showed a decrease in flexural strength. This can be attributed to the proper dispersion of NPs in the acrylic resin mass at lower concentrations and as the concentration of NPs is increased, they tend to agglomerate resulting in a decrease in the flexural strength. In addition, the presence of Zirconia NPs improves the strength with the transformation toughening mechanism. Under stresses, the Zirconia transforms from the tetragonal to monoclinic phase resulting in absorbing the energy of crack propagation, which causes an increase in strength. Also, expansion of $\mathrm{ZrO}_{2}$ crystals occurs under stress and places the crack under a state of compressive stress and arresting the crack propagation.

Mohamed et al. (2014) [7] concluded that incorporation of Zirconium oxide $\left(\mathrm{ZrO}_{2}\right)$ nanofiller powder with different concentrations $(1.5 \%, 3.0 \%, 5.0 \%$ and $7.0 \%)$ increased the flexural strength of PMMA. They demonstrated the best mechanical properties with the addition of $7.0 \%$ wt $\mathrm{ZrO}_{2}$ concentration. Zhang et al. (2014) [8] and Mohammed et al. (2012) [9] also proved that the addition of modified nano-zirconium oxide improved the mechanical properties of heat-cured acrylic denture base material. in the present study, contrary to the results found in previous studies, desirable flexural strength was achieved by adding 2.5 wt $\%$ nano $\mathrm{ZrO}_{2}$ concentration, which is a lower concentration when compared to earlier literature.

This study also compared the flexural strength of PMMA reinforced with different concentrations of nano-cellulose. PMMA reinforced with 5.0wt.\% nano cellulose showed the highest mean flexural strength (71.47 MPa). Talari et al. (2016) [10] proved that the addition of nano cellulose Particles (1.0, 2.5, $5.0 \mathrm{wt} \%$.) into the auto-polymerized temporary fixed restoration resin resulted in an increase of flexural strength in all weight percentages, where the most notable increase was observed with the $2.5 \mathrm{wt} \%$. Contrary to the results found in the above study, desirable flexural strength was achieved by adding 5.0wt.\% nano cellulose in the present study.

In the present study, intergroup comparison between the $\mathrm{PMMA}+$ nanoZrO$_{2}$ and $\mathrm{PMMA+nanocellulose}$ showed that $2.5 \% \quad \mathrm{ZrO}_{2}$ has the highest flexural strength compared to $5.0 \%$ cellulose. The results were statistically significant (0.038). One of the reasons for improved mechanical properties is due to the addition of nanoparticles is due to high interfacial shear 
strength and good bonding between the resin matrix and nanofillers which prevents crack propagation, enhancing the mechanical properties [11-13].

When impact strength was compared, PMMA reinforced with $1.5 \mathrm{wt} \% \mathrm{ZrO}_{2}$ showed the highest mean impact strength (1.34) KJ/m². Ihab et al. (2011) [14] proved that impact strength of PMMA modified with Zirconium oxide $\left(\mathrm{ZrO}_{2}\right)$ nanofillers in different percentages improves the impact strength; the maximum was observed with $5.0 \mathrm{wt} \%$ of nanoZrO $\mathrm{H}_{2}$. Sajida Begum et al. (2019) [15] concluded that PMMA reinforced with $\mathrm{ZrO}_{2}$ nanoparticles decreases the impact strength with increased concentration of $\mathrm{ZrO}_{2}$ and impact strength was found to be least at $7.0 \mathrm{wt} \%$ concentration. Contrary to the earlier literature, the present study showed that PMMA reinforced with 1.5 wt.\% $\mathrm{ZrO}_{2}$ showed the highest mean impact strength $(1.34$ $\mathrm{KJ} / \mathrm{m}^{2}$ ).

Among the nanocellulose reinforced group, the specimens with $2.5 w t \%$ nanocellulose showed the highest mean impact strength. Shenggui Chen et al. (2018) [16] concluded that the addition of $2.5 \mathrm{wt}$.\% nanocellulose improve the impact resistance PMMA composite resins. Intergroup comparison between the PMMA + nanoZrO $\mathrm{Zr}_{2}$ and PMMA + nanocellulose showed that $2.5 \%$ cellulose had the highest impact strength compared to $1.5 \mathrm{wt} \% \mathrm{ZrO}_{2}$.

The present study also compared the translucency of PMMA + nanoZrO 2 and PMMA + nanocellulose at different concentrations. The translucency of the denture base of a removable prosthesis determines its esthetic outcome. This desired level of translucency imparts the chameleon effect, which is created due to the harmonious optical properties between the underlying mucosa and the denture base of the removable prosthesis [17]. Translucency is defined as the ability of a material to permit some light to pass through its structure, thus allowing the background underneath to show through [5]. Light transmittance was considered as a translucency parameter. Light transmittance in percentage was measured using UV Visible Spectrophotometer.

Among the PMMA + nanoZrO ${ }_{2}$ group, PMMA reinforced with 1.5 wt.\% nanoZrO $\mathrm{H}_{2}$ showed the highest mean translucency. The translucency parameter was reduced as the nanoZrO $\mathrm{Zr}_{2}$ concentration increased. These results were in agreement with the study con- ducted by Mohammed M Gad (2018) [5] concluded that the addition of nano $\mathrm{ZrO}_{2}$ reduced the translucency of the PMMA as the concentration of nanoZrO $\mathrm{Zr}_{2}$ increased. Similar results were quoted by Aszrin et al. in (2016) [18]. This decrease in translucency could be attributed to the crystalline form of nanoZrO $\mathrm{Zn}_{2}$ (high opacity), which prevented absorbed light from passing through, lowering translucency. This change is inversely proportional to the concentration of nanoZrO $\mathrm{Zr}_{2}$ [5].

Among the PMMA + nanocellulose group, PMMA reinforced with 5.0wt.\% nano cellulose showed the highest mean translucency. Gibril et al. (2019) [19] concluded that the transmittance of Nanocomposite films (PMMA/CNC-TiO $)$ was decreased with increasing cellulose nanofiber content. This is probably due to the agglomeration of the nanofiller at higher concentrations. The optical transmittance of PMMA nanocomposites decreased with increasing $\mathrm{CNC}-\mathrm{TiO}_{2}$ content, especially with the high content of nanofiller.

Contrary to the results found in previous studies, the present study showed PMMA reinforced with 5.0wt.\% nano cellulose showed the highest mean translucency. Since the refractive index of PMMA (1.4813) is closer to that of cellulose (1.54) translucency is increased. In this study intergroup comparison between the PMMA + nanoZrO$_{2}$ and PMMA + nanocellulose showed that $5.0 \%$ cellulose has the highest translucency compared to $1.5 \% \mathrm{ZrO}_{2}$. The results were statistically significant $(p=0.0073)$.

The difference between the refractive indices of the fillers and matrix affects the refraction and reflection of light at the filler/matrix interface, which affects the translucency of the nanocomposite. It was found that the refractive index (RI) of the nanoZrO $\mathrm{Zr}_{2}(2.1750)$ is higher than that of the PMMA (1.4813) [5]. Since this nanocomposite (PMMA + nanozirconia) was composed of resin and inorganic nanoparticles, the higher the difference in refractive index between the two phases, the greater is the opacity of the nanocomposite [5]. The increased translucency in the PMMA + nanocelulose specimens can be attributed to their lower RI compared to nano $\mathrm{ZrO}_{2}$. Further, nano cellulose $\mathrm{RI}$ is almost the same as that of PMMA.

However, this study evaluated the effect of $\mathrm{ZrO}_{2}$ and cellulose nanoparticles incorporation on the properties of denture base resins with only three concentra- 
tions. Further studies may be focused on by incorporating a few more concentrations of these NPS and evaluating their effect on the physical and mechanical properties of denture base acrylic resins. Studies must also be concentrated on optimising a precise concentration of nano zirconia and nanocellulose particles so that superior mechanical and aesthetic qualities may be achieved.

\section{Conclusion}

Within the limits of the study, the following conclusions were drawn:

1. $\mathrm{PMMA}+$ nanoZrO $\mathrm{H}_{2}$ has the highest flexural strength compared to PMMA + nanocellulose, especially at a concentration of $2.5 \%$ nano $\mathrm{ZrO}_{2}$.

2. PMMA + nano cellulose at a concentration of $2.5 \%$ has the highest impact strength compared to PMMA + nanoZrO 2 .

3. PMMA + 5.0wt.\% nanocellulose has the highest translucency compared to PMMA + nano $\mathrm{ZrO}_{2}$.

Conflicts of interest: Authors declared no conflicts of interest.

\section{Financial support: None}

\section{References}

1. Meng TR, Latta MA. Physical properties of four acrylic denture base resins. J Contemp Dent Pract. 2005;6(4):93-100.https://doi.org/10.5005/jcdp-6-4-93

2. John J, Gangadhar SA, Shah I. Flexural strength of heat-polymerized polymethyl methacrylate denture resin reinforced with glass, aramid, or nylon fibers. J Prosthet Dent. 2001;86(4):424-7. https:// doi.org/10.1067/mpr.2001.118564

3. Alla R, Raghavendra KN, Vyas R, Konakanchi A. Conventional and contemporary polymers for the fabrication of denture prosthesis: part I - overview, composition and properties. Int J Appl Dent Sci. 2015; 1:82-89.

4. Somani MV, Khandelwal M, Punia V, Sharma V. The effect of incorporating various reinforcement materials on flexural strength and impact strength of polymethylmethacrylate: A meta-analysis. J Indian Prosthodont Soc. 2019; 19(2): 101-12. https:// doi.org/10.4103/jips.jips_313_18

5. Gad MM, Abualsaud R, Rahoma A, Al-Thobity AM, Al-Abidi KS, Akhtar S. Effect of zirconium oxide nanoparticles addition on the optical and tensile properties of polymethyl methacrylate denture base material. Int J Nanomedicine. 2018;13:283-92. https://
doi.org/10.2147/IJN.S152571

6. Jain V, Arora N, Chawla A, Mathur VP. Effect of Addition of Sapphire (Aluminium Oxide) or Silver Fillers on the Flexural Strength Thermal Diffusivity and Water Sorption of Heat Polymerized Acrylic Resins. International Journal of Prosthodontics and Restorative Dentistry. 2011; 1(1): 21-7. https:// doi.org/10.5005/jp-journals-10019-1004

7. Ashour M, Ebrahim M. Effect of Zirconium Oxide Nano-Fillers Addition on the Flexural Strength, Fracture Toughness, and Hardness of Heat-Polymerized Acrylic Resin. World Journal of Nano Science and Engineering. 2014;04:50-7. https://doi.org/10.4236/ wjnse. 2014.42008

8. Xy Z, Xj Z, Zl H, Bs Z, Rr C. Hybrid effects of zirconia nanoparticles with aluminum borate whiskers on mechanical properties of denture base resin PMMA. Dent Mater J. 2014; 33(1): 141-6. $\underline{\text { https:// }}$ doi.org/10.4012/dmj.2013-054

9. Mohammed D, Mudhaffar M. Effect of modified zirconium oxide nano-fillers addition on some properties of heat cure acrylic denture base material. J Baghdad Coll Dent. 2012;24(4):1-7.

10. Talari F, Qujeq D, Amirian K, Ramezani A, Pourkhalili H, Alhavaz A. Evaluation the Effect of Cellulose Nanocrystalline Particles on Flexural Strength and Surface Hardness of Autoploymerized Temporary Fixed Restoration Resin. Int J Adv Biotechnol Res. 2016;7:152-60.

11. Kul E, Aladağ Lİ, Yesildal R. Evaluation of thermal conductivity and flexural strength properties of poly (methyl methacrylate) denture base material reinforced with different fillers. J Prosthet Dent. 2016;116(5):803-10. https://doi.org/10.1016/ j.prosdent.2016.03.006

12. Vojdani M, Bagheri R, Khaledi AAR. Effects of aluminum oxide addition on the flexural strength, surface hardness, and roughness of heat-polymerized acrylic resin. J Dent Sci. 2012;7(3):238-44. https:// doi.org/10.1016/j.jds.2012.05.008

13. Abdallah R. Evaluation of polymethyl methacrylate resin mechanical properties with incorporated halloysite nanotubes. J Adv Prosthodont. 2016;8:167. https://doi.org/10.4047/jap.2016.8.3.167.

14. Ihab NS, Moudhaffar M. Evaluation of the effect of modified nano-fillers addition on some properties of heat cured acrylic denture base material. J Baghdad Coll Dent. 2011;23(3):23-9.

15. Begum SS, Ajay R, Devaki V, Divya K, Balu K, Kumar PA. Impact Strength and Dimensional Accuracy of Heat-Cure Denture Base Resin Reinforced With ZrO2 Nanoparticles: An In Vitro Study. J Pharm Bioallied Sci. 2019 (Suppl 2):S365-70. $\underline{\text { https:// }}$ doi.org/10.4103/JPBS.JPBS $36 \quad 19$

16. Chen S, Yang J, Jia Y-G, Lu B, Ren L. A Study of 3D-Printable Reinforced Composite Resin: PMMA Modified with Silver Nanoparticles Loaded Cellulose 
Nanocrystal. Materials (Basel). 2018;11(12). https://

doi.org/10.3390/ma11122444

17. Ahmed MA, Ebrahim MI. Effect of zirconium oxide nano-fillers addition on the flexural strength, fracture toughness, and hardness of heat-polymerized acrylic resin. World Journal of Nano science and Engineering. 2014;4(02):50. $\quad$ https://doi.org/10.4236/ wjnse. 2014.42008

18. Aszrin FN, Takarini V, Hasratiningsih Z, Purwasasmita BS. Translucency Evaluation of Polymethyl Methacrylate (PMMA) Reinforced with $\mathrm{ZrO}_{2-}$ $\mathrm{Al}_{2} \mathrm{O}_{3}-\mathrm{SiO}_{2}$ Filler System in Fabricating Indirect Restoration. UI Proceedings on Health and Medicine. 2017;1(0):48-52. https://doi.org/10.7454/ uiphm.v1i0.23

19. Gibril, M.E., Ahmed, K., Lekha, P., Sithole, B., Khosla, A. and Furukawa, H., 2019. Effect of nanocrystalline cellulose and zinc oxide hybrid organicinorganic nanofiller on the physical properties of polycaprolactone nanocomposite films. Microsyst Technol. 2019:1-0. https://doi.org/10.1007/s00542-019$\underline{04497-\mathrm{x}}$ 